\title{
Home invasive mechanical ventilation in Finland in 2015-2019
}

\author{
Petra Kotanen (10) ${ }^{1,2}$, Hanna-Riikka Kreivi (1) ${ }^{1}$, Aki Vainionpää ${ }^{3}$, \\ Hannu Laaksovirta ${ }^{4}$, Pirkko Brander ${ }^{1}$ and Waltteri Siirala ${ }^{5}$
}

Affiliations: ${ }^{1} \mathrm{HUH}$ Heart and Lung Center, Helsinki University Hospital and University of Helsinki, Helsinki, Finland. ${ }^{2}$ Doctoral Programme in Clinical Research, University of Helsinki, Helsinki, Finland. ${ }^{3}$ Department of Rehabilitation, Seinäjoki Central Hospital, Seinäjoki, Finland. ${ }^{4} \mathrm{HUH}$ Neurocenter, Helsinki University Hospital and University of Helsinki, Helsinki, Finland. ${ }^{5}$ Dept of Anaesthesiology and Intensive Care, Turku University Hospital and University of Turku, Turku, Finland.

Correspondence: Petra Kotanen, HUH Heart and Lung Center, University of Helsinki and Helsinki University Hospital, P.O. Box 372 (Haartmaninkatu 4), FI-00029 HUS, Finland. E-mail: petra.kotanendahus.fi

\section{ABSTRACT}

Introduction: The prevalence of long-term invasive mechanical ventilation via tracheostomy in chronic respiratory insufficiency is largely unknown. We aimed to clarify prevalence and aetiology of the use of home invasive mechanical ventilation (HIMV) in Finland in 2015-2019.

Methods: Information on HIMV patients was collected yearly from all Finnish Hospital District patient registries between 1 January 2015 and 1 January 2019. Data included underlying diagnosis, time from diagnosis to HIMV initiation, treatment length, mortality and basic sociodemographic data.

Results: In 2015, we had 107 HIMV patients. During the follow-up we received 34 new patients (24.1\%) and 46 patients (32.6\%) died. In 2019, we had 95 HIMV patients and the prevalence in Finland was 2.0 in 100000 . The most common diagnoses were motor neurone disease $(29.1 \%)$ and spinal cord injuries (19.9\%). Mean duration of HIMV among all patients on 1 January 2019 was 12.3 years and among deceased patients, 11.2 years. Treatment durations ranged from 7.7 years for motor neurone disease patients to 47.3 years for post-polio syndrome patients. Most patients (81.6\%) used HIMV 24 h.day ${ }^{-1}$.

Conclusions: HIMV is a rare, long-lasting treatment, most often used in chronic hypoventilation caused by chronic neurological disease. Based on our 4 year follow-up the prevalence of HIMV seems to be diminishing in Finland. Treatment duration and survival vary greatly depending on the underlying diagnosis. Most of the patients were totally dependent on HIMV, requiring 24-h care.

@ERSpublications

Home invasive mechanical ventilation is a rare treatment; in 2019, the prevalence in Finland was 2.0 in 100000 . The treatment durations are long, averaging 12 years, but the duration and survival vary greatly depending on the underlying diagnosis. https://bit.ly/3bAT9aT

Cite this article as: Kotanen $\mathrm{P}$, Kreivi H-R, Vainionpää A, et al. Home invasive mechanical ventilation in Finland in 2015-2019. ERJ Open Res 2020; 6: 00223-2020 [https://doi.org/10.1183/ 23120541.00223-2020].

Data availability: The data that support the findings of this study are available on request from the corresponding author. The data are not publicly available due to privacy or ethical restrictions.

Received: 27 April 2020 | Accepted after revision: 1 Sept 2020

Copyright $\odot$ ERS 2020. This article is open access and distributed under the terms of the Creative Commons Attribution Non-Commercial Licence 4.0. 


\section{Introduction}

Home mechanical ventilation (HMV) is a long-term treatment often used for patients with chronic respiratory insufficiency. HMV can be delivered noninvasively via an interface (noninvasive ventilation (NIV)) or invasively via an artificial airway to the trachea (invasive mechanical ventilation (IMV)). NIV is today a common and simple method for assisted ventilation that can be used by patients themselves, whereas IMV is a method of life-support ventilation, requiring more technology skills and 24-h caregiving, accruing annual costs of $€ 250000-400000$ in Finland.

Finland has enacted legislation to guarantee equal rights for HIMV-dependent patients regardless of the patient's socioeconomic status, religious or underlying diagnosis leading to HIMV [1]. The government covers all costs and the treatment is coordinated by specialised medical care regardless of where the patient is living (i.e. at home or in hospital). A team of registered nurses continuously attends to the patient. The history of this legislation derives from the 1950s, when poliomyelitis patients benefited from mechanical ventilation first by the iron lung and then via tracheostomy. Despite the long history, we do not have a national register for HIMV patients.

According to our previous national research, in January 2015 we had 107 Finnish ventilator-dependent patients. Most of these patients had a neurological disease or spinal cord injury (SCI). However, we have recognised that the prevalence of HIMV is largely unknown also internationally [2]. We have found some studies, in which the HMV prevalence has ranged from 2.9 in 100000 in Hong Kong [3] to 19.9 in 100000 in Norway [4] and the range in HIMV prevalence seems to be even greater. Thus, the aim of this study was to clarify the use of HIMV among the Finnish population and the characteristics of study patients in 2015-2019.

\section{Methods}

\section{Study design and statistical analysis}

This study was a register-based retrospective, cross-sectional study. Data for Finnish HIMV patients were collected once a year, on 1 January 2015-2019. The prevalence of HIMV was analysed at the beginning and the end of follow-up (1 January 2015 and 1 January 2019, respectively). According to Finnish legislation, patients' consent is not required for register studies in Finland. The Medical Ethics Committee of the Hospital District of South-West Finland approved the study protocol (study number 97/1802/2014).

We gathered information of the diagnosis leading to HIMV, time from diagnosis to HIMV initiation, length of HIMV, mortality and weaning during the 4-year follow-up period, and basic sociodemographic data by sending a questionnaire to all five university hospital areas treating adult (aged 16 years and over) HIMV patients. All patients requiring bi-level positive pressure or volume-cycled ventilation delivered via a tracheostomy for over 3 months were included in the study. Patients with a tracheostomy not requiring mechanical ventilation and those who were under 16 years of age were excluded. Because data were collected only once a year, it is possible that some patients were overlooked. These would be patients whose treatment was over 3 months, but had ended before the next January. Information on Finland's population is from Statistic Finland, a Finnish governmental authority. The population of Finns aged 16 years and over was 4610030 on 31 December 2018 and 4491947 on 31 December 2014.

Patients were divided into six diagnostic groups according to the underlying disease: motor neurone disease (including motor neurone disease, amyotrophic lateral sclerosis (ALS) and spinal muscular atrophy), Duchenne muscular dystrophy (DMD), post-polio syndrome, SCI (including both traumatic and nontraumatic injuries), other muscular diseases and miscellaneous. For the diseases contained within the muscular diseases and miscellaneous groups, see figure 3. Statistical analysis was conducted using SPSS, version 25 (IBM SPSS Statistics). Results are shown as $\mathrm{n}(\%)$ or mean values \pm SD.

\section{Results}

All five university hospital areas, representing a population of 4.6 million inhabitants, answered our questionnaire. On 1 January 2015, we had 107 patients and at the end of the study we had 95 patients. During the study period from 1 January 2015 to 1 January 2019 the prevalence of HIMV in Finland decreased from 2.4 in 100000 to 2.0 in 100 000. On 1 January 2019, the geographical prevalence of HIMV in the five university hospital areas ranged from 1.5 to 3.4 in 100000 (figure 1). During the 4-year follow-up we received 34 new patients, 46 patients died and 3 were successfully weaned from HIMV (figure 2). Altogether, we had 141 patients in the study. The number and proportion of all our HIMV patients are shown in table 1 . In both the new and the deceased patients, the largest diagnosis group was motor neurone disease $(32.4 \%$ and $34.8 \%$, respectively).

The most common diagnostic groups were motor neurone disease $(29.1 \%, \mathrm{n}=41)$ and SCI $(19.9 \%, \mathrm{n}=28)$ (figure 3). Data on patient age at diagnosis and at HIMV initiation, the time from diagnosis to HIMV 
FIGURE 1 Prevalence of home mechanical ventilation in Finland on 1 January 2019. Mean prevalence of home mechanical ventilation in five university hospital areas in Finland. The mean prevalence in Finland was 2.0 in 100000 inhabitants. The mean population was 4.6 million adults (2018). OUH: Oulu University Hospital; KUH: Kuopio University Hospital; TAUH: Tampere University Hospital; TUH: Turku University Hospital; HUH: Helsinki University Hospital.

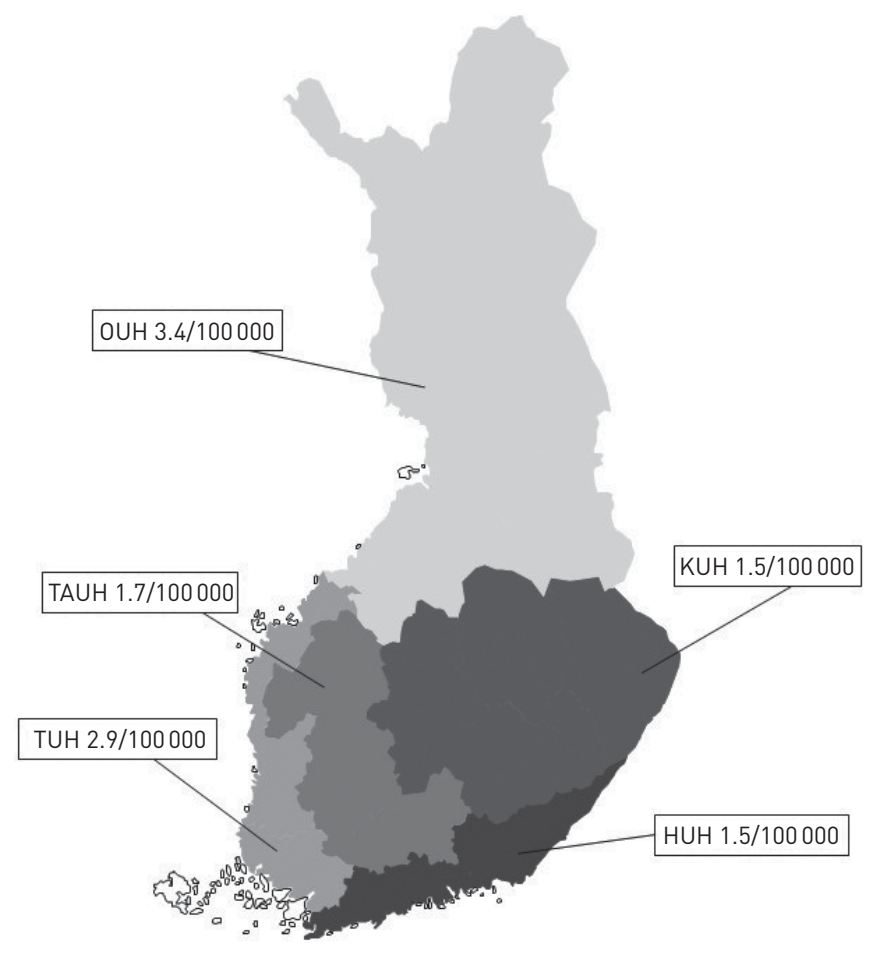

initiation, the duration of HIMV and characteristics of the deceased on 1 January 2019 are shown in table 2. The mean duration of HIMV treatment was 12.3 years and for the deceased, 11.2 years, but treatment times varied largely from 7.7 years for the motor neurone disease group to 47.3 years for the post-polio syndrome group. At treatment initiation, the patients were on average 42.9 years of age, but the ages ranged from 28.4 years for DMD patients to 56.5 years for motor neurone disease patients (table 2). The majority (68.1\%) of patients lived at home with a specialised nurse team. The rest of the patients lived in nursing homes (14.2\%), hospitals $(9.2 \%)$ or municipality health centres $(8.5 \%)$. The speciality of the treating doctor varied; a neurologist treated $46.8 \%$ of patients and a pulmonologist $34.0 \%$. HIMV was initiated electively for $34.1 \%$ $(\mathrm{n}=47)$ of the patients and $81.6 \%(\mathrm{n}=110)$ were fully HIMV-dependent.

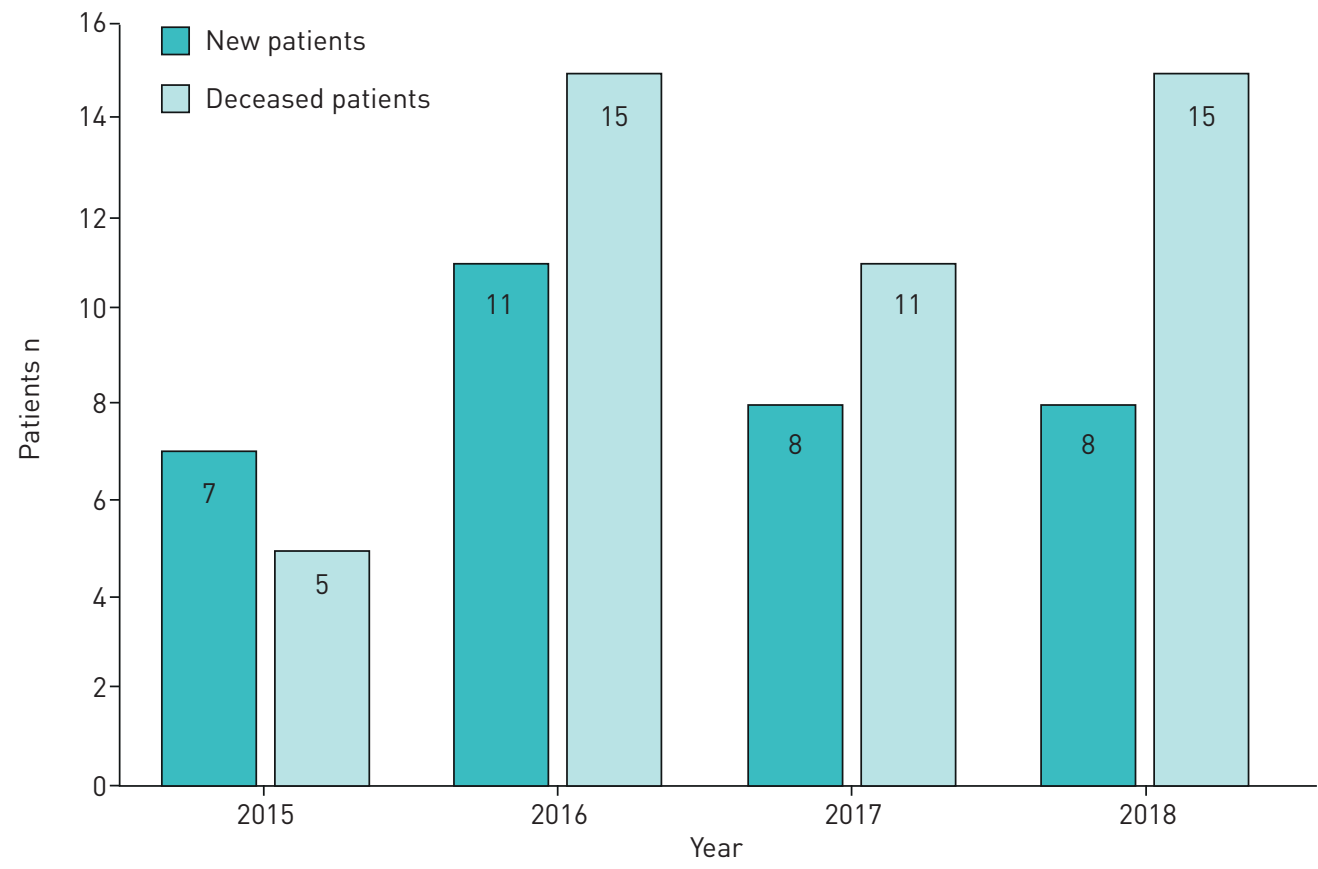

FIGURE 2 New and deceased home invasive mechanical ventilation patients in Finland in 2015-2019. 
TABLE 1 Number and proportion of all home mechanical ventilated patients in Finland in 2015-2019

\begin{tabular}{|c|c|c|c|c|c|c|}
\hline & Patients & $\begin{array}{c}\text { New } \\
\text { patients }{ }^{\#}\end{array}$ & $\begin{array}{l}\text { Deceased } \\
\text { patients }\end{array}$ & $\begin{array}{l}\text { Fully HIMV-dependent } \\
\text { patients }^{+}\end{array}$ & Male & $\begin{array}{c}\text { Electively initiated } \\
\text { HIMV }\end{array}$ \\
\hline All patients ${ }^{\S}$ & $141(100 \%)$ & 34 & 46 & $110(82 \%)$ & $91(67 \%)$ & $47(34 \%)$ \\
\hline Spinal cord injury & $28(20 \%)$ & 8 & 8 & $22(79 \%)$ & $24(86 \%)$ & $2(7 \%)$ \\
\hline Miscellaneous & $25(18 \%)$ & 5 & 8 & $16(64 \%)$ & $18(72 \%)$ & $4(16 \%)$ \\
\hline Muscular diseases & $21(15 \%)$ & 7 & 7 & $18(86 \%)$ & $12(57 \%)$ & $9(43 \%)$ \\
\hline Post-polio syndrome & $5(4 \%)$ & 0 & 2 & $4(80 \%)$ & $2(40 \%)$ & $2(40 \%)$ \\
\hline
\end{tabular}

Data are presented as $\mathrm{n}(\%)$ or $\mathrm{n}$. HIMV: home invasive mechanical ventilation. " : Patients whose treatment was initiated on 2 January 2015 to 1 January 2019; ": patients who died between 1 January 12015 and 1 January 2019; ${ }^{+}$: patients who use HIMV 24 h a day; ${ }^{\S}$ : "All patients" includes patients who were already on HIMV treatment on 1 January 2015 ( $n=107)$ and new patients whose treatment was initiated between 2 January 2015 and 1 January 2019 (n=34).

\section{Discussion}

The prevalence of HIMV in Finland was extremely low, diminishing during the 4-year follow-up. The average treatment periods were long, over 10 years. We found great variation in treatment lengths depending on the underlying diagnosis. As the treatment is long, even for the whole lifetime, it is noteworthy that since most patients are totally IMV-dependent they also need 24 -h care, which is demanding and expensive. Despite this, most of the patients were able to live at home.

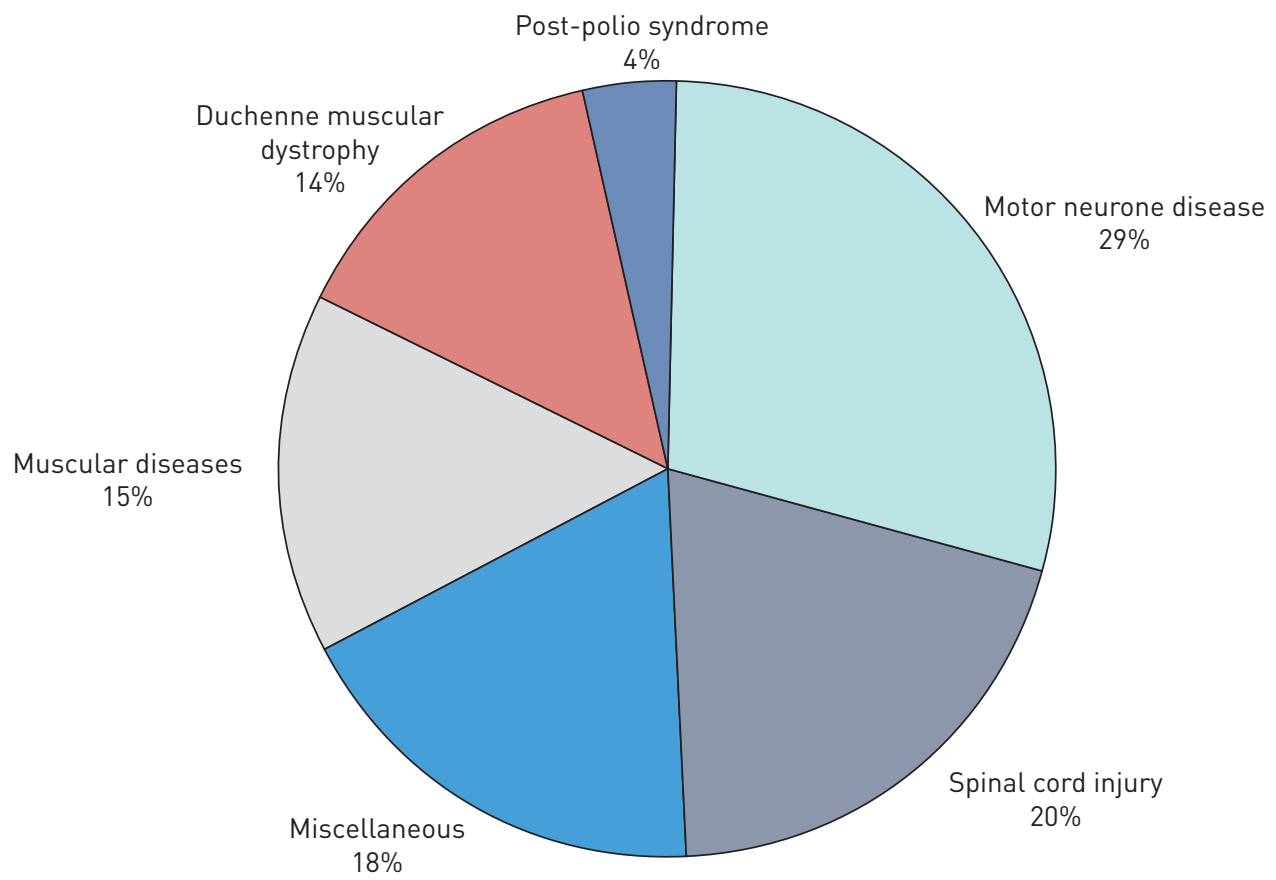

FIGURE 3 Diagnostic groups of home invasive mechanical ventilation patients on 1 January 2019. Sector diagram representing proportions of the six diagnostic groups using long-term home invasive mechanical ventilation in Finland. The motor neurone disease group includes motor neurone disease, amyotrophic lateral sclerosis and spinal muscular atrophy patients. The spinal cord injury group includes both traumatic and nontraumatic injuries. The muscular diseases group includes congenital muscular dystrophies, Becker and limb-girdle muscular dystrophies, nemaline myopathy, myotonic dystrophy and cerebral palsy. The miscellaneous group includes congenital deformities, basal ganglia disease, encephalitis, Larsen syndrome, other polymyositis, central sleep apnoea, Guillain-Barré syndrome, other polyneuropathy and other neuropathy (brain tumours and injuries, intracerebral infarctions and haemorrhages, arteriovenous malformation). 
TABLE 2 Specific data of diagnostic groups using HIMV in Finland in 2015-2019

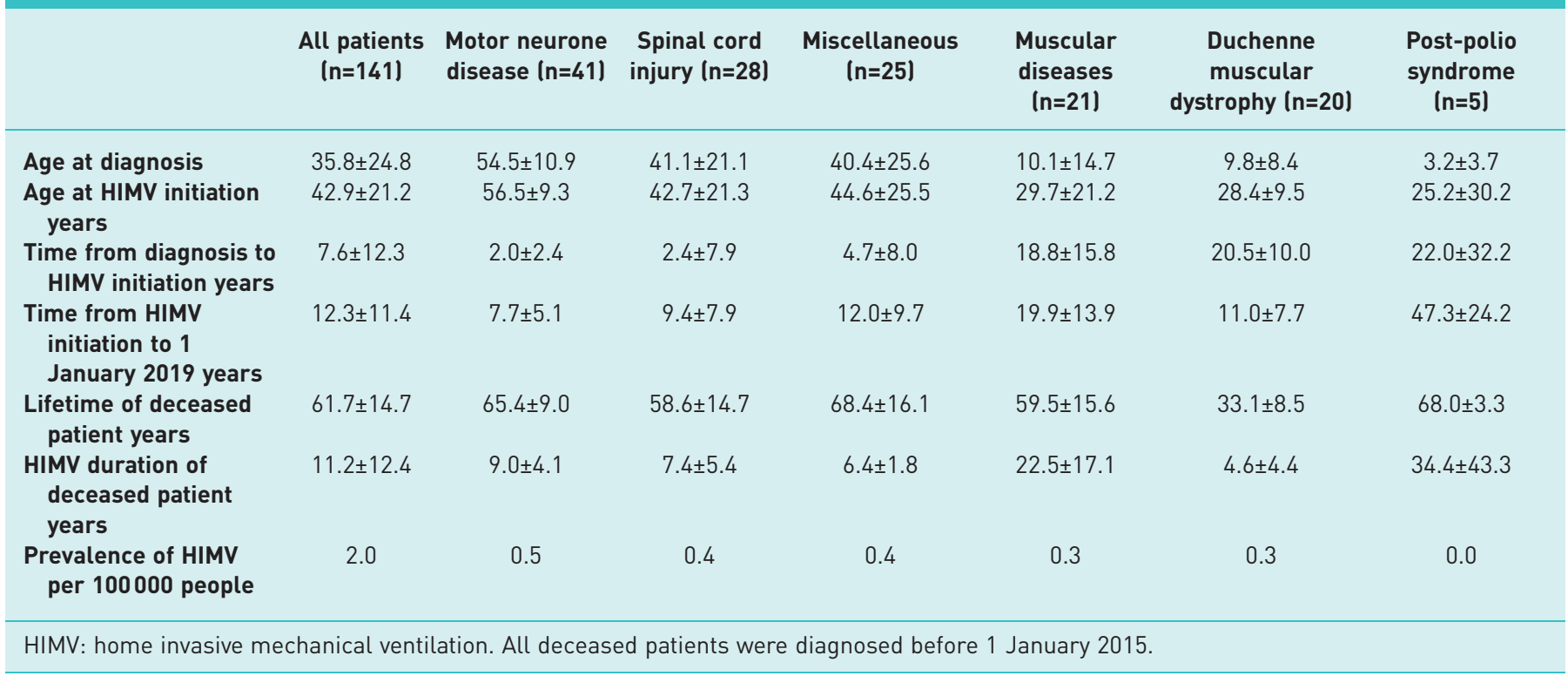

Many diseases, most commonly motor neurone disease, SCI and different muscular diseases, can lead to chronic hypoventilation and the need for HIMV treatment. Typical of these diseases is that they are currently incurable. The patients can also be divided into two categories: those with a disease leading to progressive respiratory failure and whose treatment is usually started electively, and those who failed to wean from mechanical ventilation after acute respiratory failure (e.g. SCIs) [5].

Few studies have examined the prevalence of HMV, and only a couple of countries have registers following HMV prevalence and treatment characteristics. The prevalence of HMV has been found to vary greatly between countries and also nationally [6]. In the Eurovent survey (2001-2002), the average prevalence of HMV was 6.6 in 100000 [7]. Of these patients, 13\% received invasive ventilation via tracheostomy, yielding a prevalence of 0.9 in 100000 , and the most common cause for HIMV was neuromuscular disease. The corresponding prevalence of HIMV in Australia and New Zealand was 0.5 in 100000 [8] and in the United States 0.4 in 100000 [9]. In Norway (2002-2007), the prevalence was 1.3 in 100000 [4].

However, most of the earlier studies on the HIMV prevalence are over 10 years old, and therefore, current data are not available. Sweden and Norway have registers following HMV patients. According to the Swedevox data, the prevalence of HIMV patients in Sweden was 1.3 in 100000 in 2018, but this is probably an underestimation. Patients especially with progressive neuromuscular disorder can convert from NIV to invasive ventilation without reporting the conversion to the registry. In addition, the coverage had been suboptimal during the last years (personal communication; Dr. Andreas Palm, Department of Medical Sciences, Respiratory, Allergy and Sleep Research, Uppsala, Sweden). Thus, we found the prevalence of HIMV in Finland to be similar to the Swedish results.

Reasons for the variation in prevalence are not fully known. Probably cultural and religious reasons explain some of the variation. Not all countries have precise definitions on when to initiate HMV, especially HIMV and this leaves more room for individual decision-making. Being married doubled the likelihood of proceeding to tracheostomy [10]. In addition, the caregivers' attitudes, age under 65 years and the presence or absence of advanced planning might affect the patient's decision [10, 11]. In a Norwegian study, the treating physicians' enthusiasm, knowledge and positive attitude towards HIMV were greater in the areas with high prevalence and these seemed to be important factors affecting the initiation of HIMV [6]. Moreover, regions with tertiary clinics that regularly followed the patients and densely populated areas seemed to have higher prevalence $[8,12]$. Funding for the treatment varies largely. In some countries, like Finland and Japan, the government covers all expenses, but in other countries the economic burden is substantial for the patient [10]. One reason for Finland's higher prevalence might by the Finnish legislation that guarantees everyone the possibility for HIMV, including financing the expensive treatment. Neither do we impose age restrictions for the treatment. As mentioned already in introduction, in Finland, the treatment is always arranged by special medical care and funded by the government, so the patients should have no reason to arrange the treatment in for example private medical 
care. Neither does the private sector have knowledge of organising the demanding treatment. Thus, we believe, that no long-term HIMV patients should be missing from this study. Reasons for the Finnish national variation in prevalence are probably similar to the international reasons discussed above. The majority of Finns are evangelical Lutherans, but we did not study the possible effects of religious belief, civil or socioeconomic status on HIMV initiation in Finnish patients. We also acknowledge that the small number of patients may have an effect on our results, and part of the national variation could be explained by random variation.

The last study on ALS prevalence in Finland was done in 1983, when the prevalence was 6.4 in 100000 [13]. According to our neurological authorities, the prevalence today is similar to that of Norway, 7.6 in 100000 . In our study, the prevalence of HIMV in ALS patients was 0.5 in 100000 . We found regional variation in the prevalence, from 1.6 in 100000 in Oulu to 0.2 in 100000 in Kuopio. About 5\% of all Finnish ALS patients were tracheostomised and used life-support ventilation. Their survival was long; the mean treatment duration for all motor neurone patients was 7.7 years and for those who died, 9.0 years. Internationally, ALS prevalence was about 5.2-7.6/100 000 [14-16]. In Western countries, 1.5-5\% of ALS patients underwent tracheostomy [17, 18], except in Italy, where the figure was $10.6 \%$ [19], and in Japan, even higher at about $30-39 \%[10,18]$. In other, older studies, median survival times after tracheostomy were shorter, from 0.7 to 6.2 years $[10,17,19,20]$. Internationally, the majority of ALS HIMV patients have been male $[16,18,19]$, but in our study the sex distribution was equal. HIMV treatment was started electively in only $34 \%$ of our patients. One possible explanation for the low proportion of elective IMV initiation is that about $3 \%$ of all ALS patients have respiratory-onset ALS. These patients are predominantly male, their survival times are shorter than in patients with bulbar or spinal onset ALS and their IMV start was more often unplanned [21].

The prevalence of our SCI patients has slightly increased; the prevalence was 0.4 in 100000 in 2015 and 0.43 in 100000 in 2019. The incidence of all SCIs in Finland was 9.2 in 100 000, the incidence of traumatic SCIs was 2.5-3.7 in 100000 and the incidence of nontraumatic SCIs was 5.5 in 100000 [22, 23]. In a Norwegian study, $0.4 \%$ of all SCI patients had HIMV, and the prevalence of HIMV was 0.2 in 100000 [24]. During our 4-year follow-up SCI patients were the second largest group of new patients. Because SCI is an acute event, HIMV treatment is rarely initiated electively. The most common mechanisms for traumatic SCIs are traffic accidents and high falls in younger age groups and low falls in the elderly [23]. Decreasing the number of these accidents is challenging, and prevalence will likely remain similar. Very few studies exist on the survival of HIMV-treated SCI patients. In a British 25-year retrospective study, the mean survival of SCI patients with HIMV was 10.5 years, with younger patients surviving longer [25]. Our patients' mean HIMV duration was 9.4 years and treatment duration of deceased patients was 7.4 years.

DMD and other muscular disease patients were among the youngest (average age 28.4 and 29.7 years) on HIMV treatment, initiation explained by the fact that DMD and other muscular diseases usually lead to chronic hypoventilation already in adolescence. This result is comparable to a Belgium study, where HIMV treatment started at an average age of 32.7 years [26]. The time from diagnosis to IMV initiation was long, about 20 years, so it is probable that NIV treatments, before proceeding to HIMV, were also lengthy. The treatment durations of DMD patients were long, an average of 11.0 years, and surviving patients were on average 40.3 years old on 1 January 2019. The lifetimes are comparable to other studies, where lifespan has ranged from 29 to 40 years [26-28]. In some studies, HIMV prolonged survival by 6-9 years, although some patients died because of complications associated with the tracheostomy tube [29].

The use of NIV treatment is growing rapidly. In Sweden in the 1990s and in Hong Kong at the beginning of 2000, the prevalence of HMV doubled over 5-6 years [8]. The technology of NIV treatment and mouthpiece ventilation has evolved, together with the knowledge of treating physicians, as the treatment has become more familiar [2, 14]. It seems that patients are surviving longer with NIV, and this is decreasing and postponing the initiation of HIMV. When comparing DMD patients' survival on NIV and HIMV, no survival benefit over the other treatment was found [26, 27, 30]. However, the DMD Care Considerations Working Group guideline [31] (published in 2018) recommends NIV instead of tracheostomy to optimise the patient's quality of life. In our clinics, we also have the impression that DMD and other muscular disease patients are surviving longer with NIV and the prevalence of HIMV among them is decreasing. In ALS, NIV prolongs survival, especially in patients with better bulbar function, and low-quality evidence suggests that NIV maintains quality of life [32].

Our ALS patients' treatment durations seems to be longer and in other disease groups at least equal to other studies $[10,19,20,28]$. One explanation is that in Finland all HIMV patients are considered hospital patients and a registered nurse attends to the patient continuously. Therefore, treatment of the underlying disease for HIMV as well as other possible diseases are carefully managed. It is also possible that patients 
who decide to undergo tracheostomy are healthier and more motivated in treatments than nontracheostomised patients. According to our clinical experience, we try to base all HIMV initiations on careful planning; however, as we see in our results, most of the HIMV initiations are unplanned. This may be explained by the relatively large number of patients with SCI.

\section{Limitations}

Some limitations of our study warrant discussion. We have no history of a long-term register of HIMV use in Finland, and therefore, it is possible that some patients are missing from the study. The follow-up period was short (4 years) and our sample size was relatively small at 141 patients, thus the prevalence results must be interpreted with caution. However, our findings are comparable with other international studies. We acknowledge that there might have been HIMV initiations for patients who failed to survive long enough to be registered in this study, as we only gathered patients' data once a year during the study. In this study, we did not include our NIV patients, thus we are lacking information on prevalence and characteristics of NIV-treated patients in Finland. Therefore, we were unable to compare the characteristics and survival of these patient groups.

\section{Conclusions}

HIMV prevalence in Finland is rare, 2.0 in 100000 inhabitants, and seems to be decreasing. However, the treatment durations are long, probably reflecting the good overall care of these patients. The use of NIV is increasing and this might explain the decreasing number of HIMV initiations. In the future, more research is needed to evaluate and compare the efficacy and safety of NIV and HIMV treatments and also the effect on HIMV and NIV on patients' quality of life.

Conflict of interest: P. Kotanen reports grants from The Finnish Anti-Tuberculosis Association, The Research Foundation of Pulmonary Diseases in Finland, The Väinö and Laine Kivi Foundation, and The Governmental Subsidy for Health Sciences Research, during the conduct of the study. H-R. Kreivi has nothing to disclose. A. Vainionpää has nothing to disclose. H. Laaksovirta has nothing to disclose. P. Brander has nothing to disclose. W. Siirala has nothing to disclose.

Support statement: This study was supported by Väinö ja Laina Kiven Säätiö, The Governmental Subsidy for Health Sciences Research grant Y2018SK007, Suomen Tuberkuloosin Vastustamisyhdistyksen Säätiö and the Research Foundation of Pulmonary Diseases in Finland.

\section{References}

$1 \quad$ Finnish Ministry of Justice, Decree of social and healthcare customer fees 9.10.1992/912. (legislation in Finnish). www.finlex.fi. Date last accessed: October 9, 1992

2 Siirala W, Vainionpaa A, Kainu A, et al. Prevalence of lifesupporting prolonged invasive ventilation support in Finland. Duodecim 2017; 133: 675-682.

3 Chu CM, Yu WC, Tam CM, et al. Home mechanical ventilation in Hong Kong. Eur Respir J 2004; 23: 136-141.

4 Tollefsen E, Gulsvik A, Bakke P, et al. Prevalens av hjemmerespiratorbehandling i Norge. Tidsskr Nor Laegefore 2009; 129: 2094-2097.

5 Rose L, McKim DA, Katz SL, et al. Home mechanical ventilation in Canada: a national survey. Respir Care 2015; 60: 695-704.

6 Dybwik K, Tollåli T, Nielsen EW, et al. Why does the provision of home mechanical ventilation vary so widely? Chron Respir Dis 2010; 7: 67-73.

7 Lloyd-Owen SJ, Donaldson GC, Ambrosino N, et al. Patterns of home mechanical ventilation use in Europe results from the Eurovent survey. Eur Respir J 2005; 25: 1025-1031.

8 Garner DJ, Berlowitz DJ, Douglas J, et al. Home mechanical ventilation in Australia and New Zealand. Eur Respir J 2013; 41: 39-45.

9 King AC. Long-term home mechanical ventilation in the United States. Respir Care 2012; 57: 921-930.

10 Turner MR, Faull C, Mcdermott CJ, et al. Tracheostomy in motor neurone disease. Pract Neurol 2019; 19: $467-475$.

11 Tagami M, Kimura F, Nakajima $\mathrm{H}$, et al. Tracheostomy and invasive ventilation in Japanese ALS patients: decision-making and survival analysis: 1990-2010. J Neurol Sci 2014; 344: 158-164.

12 Spataro R, Bono V, Marchese S, et al. Tracheostomy mechanical ventilation in patients with amyotrophic lateral sclerosis: clinical features and survival analysis. J Neurol Sci 2012; 323: 66-70.

13 Murros K, Fogelholm R. Amyotrophic lateral sclerosis in Middle-Finland: an epidemiological study. Acta Neurol Scand 1983; 67: 41-47.

14 Mehta P, Kaye W, Raymond J, et al. Prevalence of amyotrophic lateral sclerosis - United States, 2014. MMWR Morb Mortal Wkly Rep 2018; 67: 216-218.

15 O'Toole O, Traynor BJ, Brennan P, et al. Epidemiology and clinical features of amyotrophic lateral sclerosis in Ireland between 1995 and 2004. J Neurol Neurosurg Psychiatry 2008; 79: 30-32.

16 Nakken O, Lindstrøm JC, Tysnes OB, et al. Assessing amyotrophic lateral sclerosis prevalence in Norway from 2009 to 2015 from compulsory nationwide health registers. Amyotroph Lateral Scler Frontotemporal Degener 2018; 19: 303-310.

17 Atsuta $\mathrm{N}$, Watanabe $\mathrm{H}$, Ito $\mathrm{M}$, et al. Age at onset influences on wide-ranged clinical features of sporadic amyotrophic lateral sclerosis. J Neurol Sci 2009; 276: 163-169. 

decision-making and survival analysis: 1990-2010. Amyotroph Lateral Scler Frontotemporal Degener 2016; 17 47-54.

19 Calvo A, Ghiglione P, Mazzini L, et al. Tracheostomy in amyotrophic lateral sclerosis: a 10-year population-based study in Italy. J Neurol Neurosurg Psychiatry 2010; 81: 1141-1143.

20 Vianello A, Arcaro G, Palmieri A, et al. Survival and quality of life after tracheostomy for acute respiratory failure in patients with amyotrophic lateral sclerosis. J Crit Care 2011; 26: 329.

21 Gautier G, Verschueren A, Monnier A, et al. ALS with respiratory onset: clinical features and effects of non-invasive ventilation on the prognosis. Amyotroph Lateral Scler 2010; 11: 379-382.

22 Koskinen E, Alen M, Kallinen M, et al. Incidence of spinal cord injuries in Finland higher than expected [article in Finnish]. Lääkärilehti 2017; 39: 2160-2165.

23 Koskinen EA, Alén M, Väärälä EM, et al. Centralized spinal cord injury care in Finland: unveiling the hidden incidence of traumatic injuries. Spinal Cord 2014; 52: 779-784.

24 Tollefsen E. Respiratory complications associated with spinal cord injury. Tidsskr Nor Legeforen 2012 ; 132 : 1111.

25 Watt JWH, Wiredu E, Silva P, et al. Survival after short- or long-term ventilation after acute spinal cord injury: a single-centre 25-year retrospective study. Spinal Cord 2011; 49: 404-410.

26 Soudon P, Steens M, Toussaint M. A comparison of invasive versus noninvasive full-time mechanical ventilation in Duchenne muscular dystrophy. Chron Respir Dis 2008; 5: 87-93.

27 Boussaïd G, Lofaso F, Santos DB, et al. Impact of invasive ventilation on survival when non-invasive ventilation is ineffective in patients with Duchenne muscular dystrophy: a prospective cohort. Respir Med 2016; 115: 26-32.

28 Ishikawa Y, Miura T, Ishikawa Y, et al. Duchenne muscular dystrophy: survival by cardio-respiratory interventions. Neuromuscul Disord 2011; 21: 47-51.

29 Bach JR, Martinez D. Duchenne muscular dystrophy: continuous noninvasive ventilatory support prolongs survival. Respir Care 2011; 56: 744-750.

30 Hess DR. The growing role of noninvasive ventilation in patients requiring prolonged mechanical ventilation Respir Care 2012; 57: 900-920.

31 Birnkrant DJ, Bushby K, Bann CM, et al. Review diagnosis and management of Duchenne muscular dystrophy, part 2: respiratory, cardiac, bone health, and orthopaedic management. Lancet Neurol 2018; 17: 347-361.

32 Radunovic A, Annane D, Mk R, et al. Mechanical ventilation for amyotrophic lateral sclerosis/motor neurone disease. Cochrane Database Syst Rev 2017; 10: CD004427. 